\title{
Managing Transportation Megaproject Schedule Risks Using Structural Equation Modelling: A Case Study of Shanghai Hongqiao Integrated Transport Hub in China
}

\author{
Wei Peng ${ }^{1,2}$ and Liangfa Shen ${ }^{1,3}$ \\ ${ }^{1}$ School of Economics \& Management, Tongji University, Shanghai, China \\ ${ }^{2}$ Bank of China Investment Management Co. Ltd, Shanghai, China \\ ${ }^{3}$ Construction Science, Texas A\&M University, College Station, Texas, USA
}

\begin{abstract}
Tight schedules, multifunctional scopes, and colossal sizes usually characterize transportation megaprojects as challenging tasks for completion. In order to address these situations, a schedule risk management method was developed in this paper based on the structural equation model. In the proposed method, risk identification, evaluation and response were arranged as a sequence, and the expert elicitation technique was adopted in order to quantify the schedule risk status. To demonstrate the applicability of the proposed model, a megaproject case in China, the Shanghai Hongqiao Integrated Transport Hub (SHITH), was chosen. Information within the expanded risk register was collected including the probability and consequence of risk events, the complexity of risk responsible owners, the reaction time, and the time lasting for risk countermeasures. Final risk control results showed that the method could not only address the schedule risks correlations effectively, but also maintained the simplicity for construction management practices.
\end{abstract}

\section{Introduction}

Transportation megaprojects have currently addressed more and more public attentions due to large investment, advanced technologies and long-time construction. Megaprojects could be defined as projects costing more than $\$ 1$ billion and lasting more than five years in construction duration [1]. The typical transportation mega projects can be found all around the world such as in Europe, the Øresund Bridge between Denmark and Sweden, the Vasco da Gama Bridge in Portugal, and the German Maglev Train between Berlin and Hamburg; in Asia, Hong Kong's Chek Lap Kok Airport, China's Quinling Tunnel, Japan's Akashi Kaikyo Bridge, and Malaysia's North-South Expressway etc. The important role of transportation megaprojects has been revealed in the change of globalization and civilization [2]. Compared to ordinary projects, transportation megaprojects bear more attributes in social contexts, such as the inadequate previous experience, the economic and environmental effects, the technology innovations, the political and cultural effects, and the safety issues.

Due to the substantial impacts on communities and environment, it is important to identify and assess the schedule risks for building megaprojects [3]. For megaprojects, aligning with the original timeline and scopes could not only guarantee the missions that megaprojects hold to complete on time, but also save the public resources and protect civilian benefits [4]. As a result, transportation megaprojects are usually characterized by tight schedules, multifunctional scopes, and colossal sizes. However, the large-scale engineering, construction and infrastructure projects are usually complex and notoriously difficult to manage [5]. Schedule overrunning frequently occurs during the planning and construction phases, named the "megaproject paradox" [1]. For instance, in the United States, the Boston Central Artery/Tunnel Project, commonly known as the Big Dig, projected the official planning phase to start in 1982 and was originally scheduled for completion in 1998. Finally, however, the project was concluded on December 31, 2007, with nineyear delay.

Therefore, improving the schedule techniques of megaprojects with risk analysis has become a prospective field for transportation construction management. The remainder of the paper is structured as follows: Section 2 reviewed the existing schedule risk assessment literature in transportation project, which is set up as a steady basis for current research. Section 3 introduced the modified risk register and structural equation modeling in detail, as the two basic methods adopted in the schedule risk management model. In order to demonstrate the applicability of the proposed method, an in-depth analysis of a real-life megaproject, the Shanghai Hongqiao Integrated Transport Hub (SHITH), is presented in Section 4. The project schedule risk identification and ranking approach is outlined prior to the presentation of 
the schedule risk measurement model. The case study concludes with a discussion of SEM outputs interpretation and application in decision-making. Section 5 summarized the paper.

\section{Related studies}

Project risk is defined as an uncertain event or condition that, if occurs, has a positive or negative effect on one or more project objectives such as scope, schedule, cost and quality [6]. Risk management can thus be critical, since risks are underlying throughout the whole project life cycle. Generally, risk management is the life cycle process that includes planning, identification, analysis, response planning, and controlling risk on a project [6][8]. The objectives are to increase the likelihood and impact of positive events, and decrease the likelihood and impact of negative events in the project [6]. From a risk management perspective, construction risks such as adverse weather, poor subcontractor performance, safety and environmental risks, resource availability, and coordination among various programs need to be carefully monitored [8].

As a foundation of the risk management process, risk registers are usually used to house a complete list of risks that may be faced in one place. With dynamic documentation, the risk register is updated throughout the project as old risks are closed out and new risks are identified [6]. Traditionally, two variables of the risks, the likelihood and the consequences, were adopted in order to track the changes quantitatively [9], [10]. However, limitations exist in real application. For instance, the inner correlation or clustering between risk events generally got lost in a risk register. A warning was set against the dangers of one-sidedly using risk registers and related practices in containing management risk [11]. As a result, varied risk register improvements occurred in the risk management. Based on the standard risk register, a more stable risk prioritization measure was proposed by fusing elements of different strategies from several matrix-based schemes [12]. A combination of these schemes led to a cubic-structure, rather than a matrix, as risks are evaluated along three dimensions: impact, probability, and discrimination. The ranking model was similar to the generalized business impact analyses proposed by [13]. The first dimension, impact, was taken directly from the research of [14] and it used a five-point scale for evaluating risk impact. The second dimension, probability, was based on [15]. Also, a PIS (probability, impact and significance) method was proposed by [16], which encompassed the significance criterion into risk quantification.

Multiple risk sources might result in transportation project delay such as organization and management, economic, technique, and environment [17]. In order to address the characteristics of these underlying sources, various schedule risk management methods were adopted in the previous research. Probability theory was used to get a best-fit distribution of schedule overruns occurring in Australian constructions and engineering projects [18]. The identified probability distribution function enabled a realistic estimate of schedule overrun in schedule risk determination. A schedule risk analysis methodology was also proposed with activity-risk factor matrix and risk correlation coefficient matrix, in order to find out the pessimistic project completion time, critical activities and risk elements [19]. When coming to more complicated correlations, networks could also be adopted for analyzing the schedule risks [20]. Other hybrid risk analysis models involve the integrated risk management and proactive scheduling [21], project tracking [22], and schedule assessment and evaluation [23].

Transportation megaprojects hold close relationships with the level of political centralization and economic development, which functioned as a safety valve in society [24]. Distinguished from the previous schedule risk research, this paper presents a statistical schedule risk management method adopted by the SHITH project. In order to enhance the transportation megaproject performance, two main virtues of the method are demonstrated thusly: 1) schedule risk characteristics are addressed such as the correlations between risk events, and 2) the simplicity of methodology is maintained, which is important for real construction application. Thus, transportation megaproject owners or managers from different sectors could effectively use and implement the method in real life practice.

\section{Methodology}

\subsection{Modified risk register}

Risk Breakdown Structure (RBS) is an approach that could be considered as a hierarchically organized depiction arranged by risk categories. Following the concept of Work Breakdown Structure (WBS), RBS provides a means for the risk manager to structure the risks being addressed or tracked. Based on RBS, risk could be built as a central repository for all risks identified by the project or organization and, for each risk, includes information such as risk probability, impact, counter-measures, and so on. Concerning the schedule risks for transportation megaprojects, three major factors are included in the proposed risk register that evaluate the risk score for transportation megaprojects: 1) probability of risk events $P, 2$ ) consequence of risk events $C$, and 3) urgency of risk events U. For the urgency of risk events, three sub-factors are used for evaluation including: 1) complexity of risk responsible owners X;2) reaction time of each risk responsible party; and 3) time lasting for risk countermeasures. The modified risk register framework is demonstrated in Table 1 below for megaproject schedule risks. 
Table 1. Modified risk register framework.

\begin{tabular}{|c|c|c|c|c|c|c|c|}
\hline \multirow{3}{*}{ Risk item } & \multirow{3}{*}{ Probability } & \multirow{3}{*}{ Consequence } & & & & \multicolumn{2}{|c|}{ Risk score } \\
\hline & & & & & & \multirow[t]{2}{*}{ Urgency } & \\
\hline & & & Complexity & $\begin{array}{c}\text { Reaction } \\
\text { time }\end{array}$ & Countermeasure & & \\
\hline$K_{1}$ & $P_{1}$ & $C_{1}$ & $X_{1}$ & $R_{1}$ & $L_{1}$ & $U_{1}$ & $S_{1}$ \\
\hline$K_{2}$ & $P_{2}$ & $C_{2}$ & $X_{2}$ & $R_{2}$ & $L_{2}$ & $U_{2}$ & $S_{2}$ \\
\hline$\ldots$ & $\ldots$ & $\ldots$ & $\ldots$ & $\ldots$ & $\ldots$ & $\ldots$ & $\ldots$ \\
\hline$K_{j}$ & $P_{j}$ & $C_{j}$ & $X_{j}$ & $R_{j}$ & $L_{j}$ & $U_{j}$ & $S_{j}$ \\
\hline$\ldots$ & $\ldots$ & $\ldots$ & $\ldots$ & $\ldots$ & $\ldots$ & $\ldots$ & $\ldots$ \\
\hline$K_{n}$ & $P_{n}$ & $C_{n}$ & $X_{n}$ & $R_{n}$ & $L_{n}$ & $U_{n}$ & $S_{n}$ \\
\hline
\end{tabular}

Note: Stands for the risk index and $\mathrm{n}$ stands for the total number of risks identified in RBS, where. $j \in\{1, \ldots, \mathrm{n}\}$ For each of the above variables, survey data is collected from project managers and engineers from respective points of view. Here, $\mathrm{m}$ stands for the number of surveyed experts. Datasets are represented as .

$$
P_{j}=\left[p_{j}^{1}, p_{j}^{2}, \ldots, p_{j}^{m}\right], C_{j}=\left[c_{j}^{1}, c_{j}^{2}, \ldots, c_{j}^{m}\right], X_{j}=\left[x_{j}^{1}, x_{j}^{2}, \ldots, x_{j}^{m}\right], R_{j}=\left[r_{j}^{1}, r_{j}^{2}, \ldots, r_{j}^{m}\right], L_{j}=\left[l_{j}^{1}, l_{j}^{2}, \ldots, l_{j}^{m}\right] .
$$

\subsection{Structural equation modeling}

Structural equation modeling (SEM) technique is an extension of the general linear model that was originally developed by sociologists and psychologists. Attractive virtues of SEM include: 1) assumptions underlying the statistical analyses are testable giving the investigator full control and enabling furthering understanding of the analyses; 2) regression coefficients, means, and variances can be compared simultaneously; and 3) ability to fit nonstandard models, including longitudinal data, databases with time series analysis, and databases with nonnormally distributed variables [25]. In the construction management, SEM was used for describing and quantifying the influence of situational factors in project environments [26-27]. The SEM approach provides theoretical insight into how individual factors work together to enable the modeling of multiple latent variables that cannot be measured directly. Four geometric symbols are schematically used in SEM-a circle or ellipse, a square or rectangle, a single-headed arrow, and a double-headed arrow, each of which represents an important component in the analytic process. For instance, the circle means a latent variable, while the square symbol represents an observed variable. The single-headed arrow implies the impact of one variable on another. The doubled-headed arrow means a covariance or correlations between pairs of variables. Each variable is connected with another by single or double headed arrow.

Combining the SEM method with the modified risk register, the hypothesized second-order model sample of factorial structure for the SHITH schedule risk is represented in Fig. 1. The SHITH schedule risk model presented hypothesizes a priori that: 1) the sample schedule risks in SHITH can be explained by two factors $\mathrm{S} 1$ and S2; 2) each item-pair measure has a nonzero loading on the schedule risk factors that it was designed to measure (termed a target loading), and a zero loading on all other factors (termed non-target loadings); 3) S1 and S2 are correlated; 4) errors associated with each measure are uncorrelated. In more details, K1 and K2 are chosen to include the observed variables of (P1, C1, X1, R1, L1) and (P2, C2, X2, R2, L2). Based on the observed variables, structures of the latent variables (U1, S1) and (U2, S2) are framed. Other latent variables e1 e12 represent the measurement and residual errors. Causal effects are represented by the single-headed arrows in the path diagram. For instance, X1, R1 and L1 lead to U1, while U1, P1 and C1 lead to S1. By contrast the bidirectional arrow between $\mathrm{S} 1$ and $\mathrm{S} 2$ represents the correlations and covariance between the two risks without an explicitly defined causal direction.

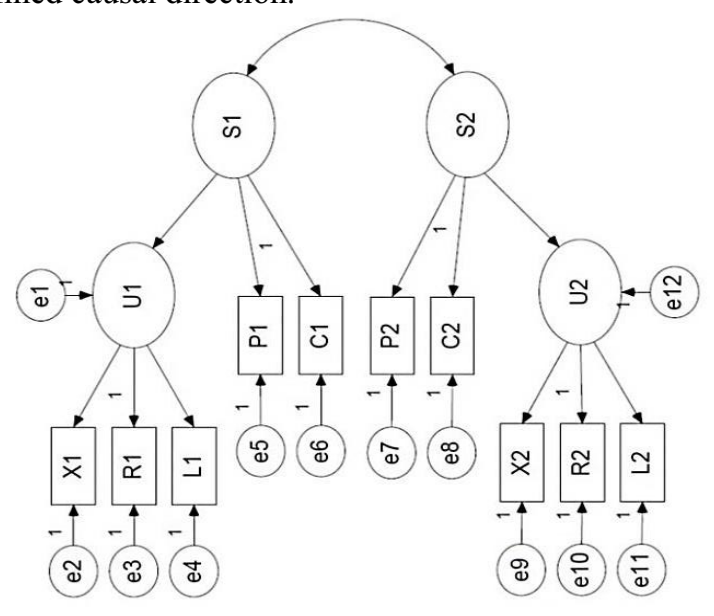

Figure 1. Example of confirmatory factor analysis measurement model for the SHITH schedule risks.

\section{Case study}

\subsection{Modified risk register}

The Shanghai Hongqiao Integrated Transport Hub (SHITH) is a super-large type of world-class transport hub that is located in west Shanghai with a total area of 26.2 square kilometers and an investment of more than $\$ 12$ billion. As a major urban infrastructure project started during the eleventh "Five-Year Plan" of China (20062010), the SHITH serves as the transit center to 
effectively connect Shanghai with other cities in the Yangtze delta area, which also supports the city's future development as an international trade, financial, shipping center. Due to the Shanghai World Expo 2010 from May to August, the SHITH project is also an important setup for facilitating the transportation service during that time. According to Fig. 2, the Shanghai Hongqiao Airport Terminal 2 SHAT2) and the Traffic Center (TC) are the two major civil projects of SHITH. For TC, there are four main subprojects: west traffic square, metro station, maglev station, and east traffic square. In general, a variety of modern transportation forms are involved, including aviation, high-speed rail lines, intercity rail lines, maglev, bus rapid transit, metro lines, etc. The railway station takes a total area of 1.3 million square meters, which is the largest railway station in Asia. Also, the Hongqiao Maglev Station is built with a scale of 10 sets and 10 lines, which is the first large maglev passenger station in China. All the facilities among the SHITH constitute as a cohesive whole. If any part was defected, the SHITH system cannot operate properly.

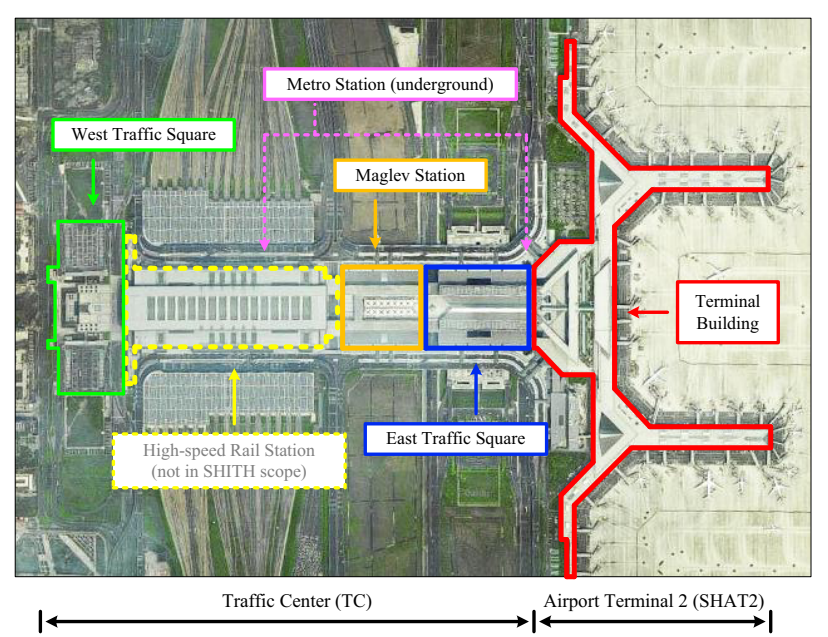

Figure 2. Layout of Shanghai hongqiao integrated transport hub (SHITH).

The overall construction work of SHITH needed to be completed within 38 months and put into public use right before the expo. In general, the SHITH project followed the original schedule plan that the SHAT2 project started in February 2007 and completed in March 2010, while the TC project started in July 2007 and completed in April 2010. Aligning with the schedule plan was thus one of the highest priorities in the SHITH project objectives. However, multiple project participants are involved making the working interfaces complex. The whole SHITH program was delivered in the form of traditional design-bid-build with 18 general contractors and 20 operating companies in total. Also, 12 different stateowned companies were involved in the co-finance activities. As a result, overlaps frequently occurred on both the construction and investment interfaces. Taking the traffic center as an example, $\$ 2.5$ billion have been spent by Shanghai Rainbow Investment Company who works as the main responsible party on the civil work, while the Shanghai Shentong Metro Group was also responsible for the construction of two metro stations. Furthermore, the construction and operation work were mostly carried out by subcontracting. It is likely that the project investors had more interfaces with the subcontractors or sub-operators, and more integration problems within a project to deal with. As a result, difficulties were added in to maintain the project schedule.

\subsection{Schedule risk management process}

In order to address the dynamic construction progress, effective risk management is a multiple-stage process through the whole construction phase. In the proposed method, three major steps are represented in Fig. 3: 1) risk identification, 2) risk evaluation, and 3) risk response, which build up updating loops for every evaluation period. In general, both Step I Risk Identification and Step II Risk Evaluation compose the risk assessment process. Risk treatment is composed by the Step III Risk Response and information updating. Two research methods are adopted so that the expert elicitation technique is used for data collecting and the SEM method is used for data analyzing.

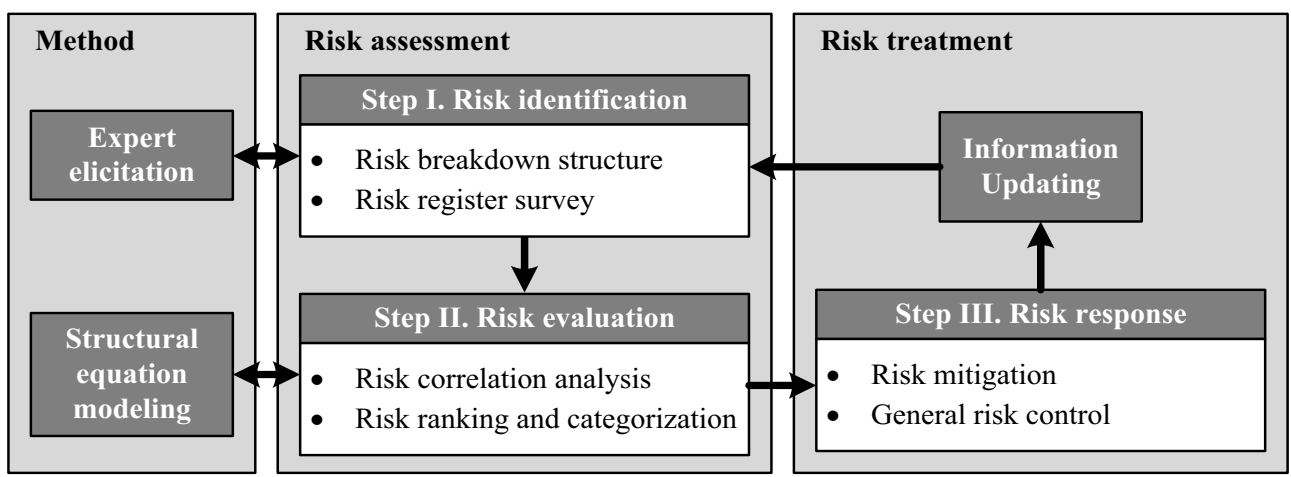

Figure 3. Conceptual framework for the SHITH schedule risk management.

\subsection{Risk identification process}

The schedule risk management model for transportation megaprojects starts with risk identification. RBS and risk register are built by categorizations in order to identify the potential schedule risks and quantify the corresponding characteristics for a certain evaluation period. The expert elicitation technique was adopted for building the RBS and risk register in accordance with the SHITH construction execution plans. First of all, experts involved were widely spread in order to cover the whole schedule risk opinions from different project perspectives, including officials from the engineering management and 
financing department of Shanghai Rainbow Investment Corp (the investor and owner of TC), department leaders from the financing, engineering, planning, IT service, and aviation sections of airport construction headquarter (airport project management department), senior project managers from construction management firm (Shanghai construction group), as well as the general contractors, designers, and supervisor relative to the SHITH construction. Other interested parties were also invited to participate in revising the drafted RBS and risk register in the last round of schedule risks investigation. Finally, the modified risk register was reported in detail to the top managerial committee of project stakeholders, such as the SHITH construction authority. Feedback was confirmed and final agreement was then reached.

The SEM program standard errors are computed under the assumption of large sample sizes. Considering the real situation of SHITH, 12 experienced experts were invited for workshop discussions and questionnaire surveys. Based on their monthly risk evaluations with repetitive but updated risk items, 40 results were collected for each item with the truncations of extra data, where $m=40$. All the invited experts have more than 15year construction experience and 11 of them have participated similar large-scale projects such as Shanghai Pudong International Airport project, Guangzhou Baiyun International Airport, thus experienced with the construction, commissioning and testing work in SHITH. The estimates on the schedule risks could be deemed as relatively highly precise though subjective. Aligning with the time table of SHITH, modified risk registers were developed respectively for SHAT2 and TC according to the primary risk sources. Taking SHAT2 for example, risks were divided into five categorizations: 1) management and organization risks; 2) technique risks; 3) economic risks; 4) law risks; and 5) safety and environmental risks, similar to TC. As shown in Table 2, 30 risk items are identified based on the expert elicitation, where $n=30$.

For the modified risk register, each expert is required to provide the numeric values concerning the probability, consequence, and urgency of risks events in the questionnaire. In order to be consistent in the evaluation scale for all experts, a Likert Scale is used and tailored to the SHITH project situation. The definition of each level in the scales is presented in Tables 3 shown below.

The first two dimensions in risk registers are regular risk probability and consequence. In order to fit the schedule risk characteristics of transportation megaprojects, a third dimension, urgency, is added in for evaluation. Three different aspects of urgency, as the complexity of risk responsible owners, the reaction time of each responsible party, and the time lasting for risk countermeasures are classified in the register. Since the numbers of responsible parties regard risk management, they normally range from 1 to 5 in the SHITH project, which is the same number adopted as in the evaluation scale. For example, stands for only 1 party involved in construction.

Based on the proposed evaluation criteria, experts gave the opinions on five aspects of the risk events: the probability, the consequence, the complexity, the reaction time, and the time lasting for risk countermeasures. From the result, unique characteristics are presented for different risk items in the risk register.

Table 2. Rbs of shat 2 with five categorizations.

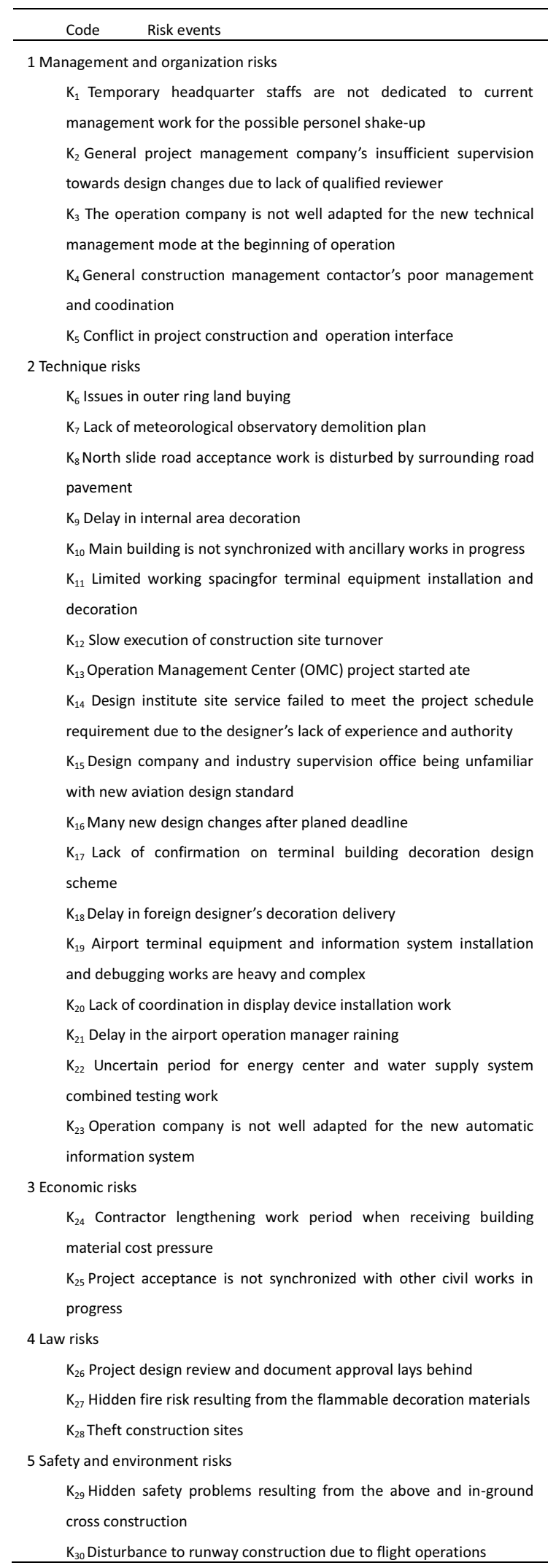

\subsection{Risk evaluation process}


Based on the survey results, SEM is framed in order to get the risk score and the corresponding correlations for risk categorization and ranking. Causations and correlations among risk events are analyzed that attempt to link the certain risks to others.

Table 3. Likert scales for measurement of the risk events.

\begin{tabular}{|c|c|c|c|}
\hline & Level & Score & Definition \\
\hline \multirow[t]{5}{*}{$\begin{array}{l}\text { Probability of } \\
\text { risk events }(\mathrm{Pj})\end{array}$} & Impossible & 1 & $\begin{array}{l}\text { Very exceptional } \\
\text { circumstances with } 20 \% \text { or } \\
\text { less chance }\end{array}$ \\
\hline & Hardly & 2 & $\begin{array}{l}\text { Unlikely to occur with } 20 \% \text { to } \\
40 \% \text { chance }\end{array}$ \\
\hline & Possibly & 3 & $\begin{array}{l}\text { Sometimes with } 40 \% \sim 60 \% \\
\text { chance }\end{array}$ \\
\hline & Very possible & 4 & $\begin{array}{l}\text { In most circumstances with } \\
60 \% \text { to } 80 \% \text { chance }\end{array}$ \\
\hline & Almost definite & 5 & $\begin{array}{l}\text { Almost certain to and } \\
\text { expected to occur with } 80 \% \text { or } \\
\text { greater chance }\end{array}$ \\
\hline \multirow{5}{*}{$\begin{array}{l}\text { Consegience of } \\
\text { risk events }(\mathrm{C})\end{array}$} & Very low & 1 & No delays or within 5 days \\
\hline & Low & 2 & Slight delay within $6-15$ days \\
\hline & Medium & 3 & $\begin{array}{l}\text { Moderate delay within } 16-30 \\
\text { days }\end{array}$ \\
\hline & High & 4 & $\begin{array}{l}\text { Considerable delay within } 31- \\
60 \text { days }\end{array}$ \\
\hline & Very high & 5 & $\begin{array}{l}\text { Serious delay with more than } \\
61 \text { days }\end{array}$ \\
\hline \multirow{5}{*}{$\begin{array}{l}\text { Complexity of risk } \\
\text { responsible owners }(\mathrm{Xj})\end{array}$} & Very simple & 1 & Single party involved \\
\hline & Simple & 2 & Single parties involved \\
\hline & Medium & 3 & Single parties involved \\
\hline & Complex & 4 & Single parties involved \\
\hline & Very Complex & 5 & Single parties involved \\
\hline \multirow[t]{5}{*}{$\begin{array}{l}\text { Reaction time of each } \\
\text { responsible party(Rj) }\end{array}$} & Very short & 1 & $\begin{array}{l}\text { No waiting time or within } 2 \\
\text { days }\end{array}$ \\
\hline & Short & 2 & Waiting time within 3-7days \\
\hline & Medium & 3 & Waiting time within $8-15$ days \\
\hline & Long & 4 & Waiting time within $15-29$ days \\
\hline & Very long & 5 & $\begin{array}{l}\text { Waiting time with more than } \\
31 \text { days }\end{array}$ \\
\hline \multirow[t]{5}{*}{$\begin{array}{l}\text { Time lasting for risk } \\
\text { countermeasures }(\mathrm{Lj})\end{array}$} & Very short & 1 & $\begin{array}{l}\text { No waiting time or within } 2 \\
\text { days }\end{array}$ \\
\hline & Short & 2 & Waiting time within $3-7$ days \\
\hline & Medium & 3 & Waiting time within $8-15$ days \\
\hline & Long & 4 & Waiting time within $15-29$ days \\
\hline & Very long & 5 & $\begin{array}{l}\text { Waiting time with more than } \\
31 \text { days }\end{array}$ \\
\hline
\end{tabular}

We state that the management and organization schedule risks model presented in Fig. 4 as an example, which hypothesizes a priori that: 1) management and organization schedule risks in SHITH can be explained by five factors: S1, S2, S3, S4 and S5; 2) each item-pair measure has a nonzero loading on the schedule risk factors that it was designed to measure (termed a target loading), and a zero loading on all other factors (termed nontarget loadings); 3 ) the five schedule risk factors are correlated; 4) errors associated with each measure are uncorrelated. Numerous iterations are conducted to achieve the inner correlations for schedule risk analysis with the support of expert investigation data as input. In order to illustrate how confirmatory factor analysis assists risk evaluation in detail, risk items are listed in the first section of RBS in Table 2, the category of management and organization risks, is chosen as an example. AMOS 17.0 software is used to quantify the relationship levels. In the simple case, 65 variables are arranged through the confirmatory factor analysis that including 25 observed variables and 40 latent variables, as Figure 4 shown below. Within the 40 latent variables, 35 of them are exogenous latent variables, and , and 5 of them, , are endogenous latent variables. Note that, the standardized estimated parameters are shown along with the arrow line. The final model concretizes the conceptual model that revealing the logical impacts that all observed and latent variables listed have on the risk scores.

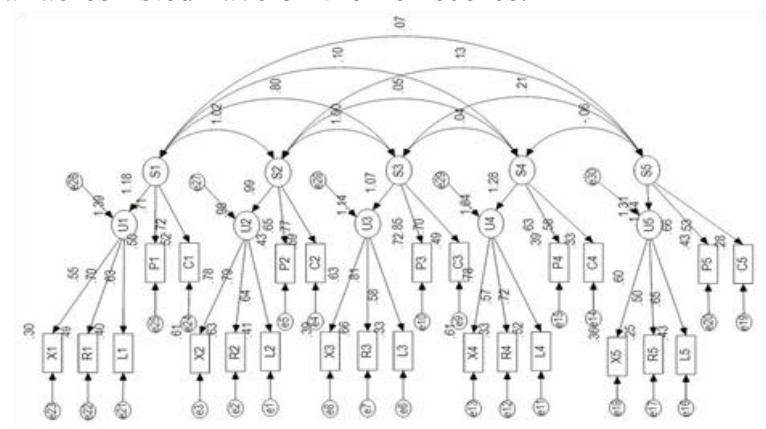

Figure 4. Output of confirmatory factor analysis measurement model for the management and organization schedule risks in SHITH.

Taking the risk item as an example, among the three observed variables having influence $($ coefficient $=0.70)$ set the most significant effect, then followed by $($ coefficient $=0.63)$ and $($ coefficient $=0.55)$. Similar to , (coefficient $=1.18)$ is the most significant factor setting influence, then followed by (coefficient $=0.72$ ), and (coefficient $=0.71)$. The same analysis could also be applied to the risk items, and . Detailed correlation analysis is shown in Table 4 and the estimations are demonstrated to be statistically significant. Estimation of the Regression Weights/ Result of Factor Analysis.

Correlations among different risk items are also shown in Table 5. Taking the covariances of S1 and S2 as examples, the estimate is 1.065 and the standard error is 0.322 . Since C.R. $=3.313$ that is greater than 2 , and $\mathrm{p}<0.001$, the correlation between $\mathrm{S} 1$ and $\mathrm{S} 2$ is very significant at the 0.0001 level. Thus, risk items could be taken care at the same time. Based on the analysis, and are closely correlated, while and are relatively independent.

Table 4. Correlations among different risk items.

\begin{tabular}{|c|c|c|c|c|c|c|}
\hline \multicolumn{2}{|c|}{ Latent variable } & Observed & Estimate & S.E. & C.R. & $\mathrm{P}$ \\
\hline & U1-> & $\mathrm{X} 1$ & 0.994 & 0.260 & 3.822 & $* * *$ \\
\hline & U1-> & $\mathrm{R} 1$ & 0.935 & 0.206 & 4.541 & $* * *$ \\
\hline & U1-> & L1 & 1.000 & & & \\
\hline S1-> & U1-> & & 0.859 & 0.184 & 4.657 & $* * *$ \\
\hline S1-> & & P1 & 0.724 & 0.164 & 4.419 & $* * *$ \\
\hline S1-> & & C1 & 1.000 & & & \\
\hline & U2-> & $\times 2$ & 1.297 & 0.281 & 4.622 & $* * *$ \\
\hline
\end{tabular}




\begin{tabular}{|c|c|c|c|c|c|c|}
\hline & U2-> & $\mathrm{R} 2$ & 1.375 & 0.293 & 4.690 & $* * *$ \\
\hline & U2-> & L2 & 1.000 & & & \\
\hline S2-> & U2-> & & 0.798 & 0.176 & 4.543 & $* * *$ \\
\hline S2-> & & P2 & 0.930 & 0.197 & 4.727 & $* * *$ \\
\hline \multirow[t]{4}{*}{ S2-> } & & $\mathrm{C} 2$ & 1.000 & & & \\
\hline & U3-> & X3 & 1.006 & 0.296 & 3.402 & $* * *$ \\
\hline & U3-> & R3 & 1.304 & 0.323 & 4.032 & $* * *$ \\
\hline & U3-> & L3 & 1.000 & & & \\
\hline S3-> & U3-> & & 0.955 & 0.261 & 3.667 & $* * *$ \\
\hline S3-> & & P3 & 1.159 & 0.229 & 5.065 & $* * *$ \\
\hline \multirow[t]{4}{*}{ S3-> } & & C3 & 1.000 & & & \\
\hline & U4-> & $\mathrm{X} 4$ & 1.166 & 0.248 & 4.712 & $* * *$ \\
\hline & U4-> & R4 & 0.712 & 0.211 & 3.423 & $* * *$ \\
\hline & U4-> & L4 & 1.000 & & & \\
\hline S4-> & U4-> & & 1.449 & 0.518 & 2.797 & $.005^{* *}$ \\
\hline S4-> & & P4 & 0.890 & 0.241 & 3.688 & $* * *$ \\
\hline \multirow[t]{4}{*}{ S4-> } & & $\mathrm{C} 4$ & 1.000 & & & \\
\hline & U5-> & X5 & 0.883 & 0.291 & 3.038 & $.002^{* *}$ \\
\hline & U5-> & R5 & 0.794 & 0.306 & 2.593 & $.100 * *$ \\
\hline & U5-> & $\mathrm{L} 5$ & 1.000 & & & \\
\hline S5-> & U5-> & & 1.416 & 0.596 & 2.376 & $.015^{* *}$ \\
\hline S5-> & & P5 & 0.965 & 0.338 & 2.854 & $.004 * *$ \\
\hline S5-> & & $\mathrm{C} 5$ & 1.000 & & & \\
\hline
\end{tabular}

Note: ${ }^{*} \mathrm{p}<0.1 ; \quad{ }^{* *} \mathrm{p}<0.05 ; \quad{ }^{* * *} \mathrm{p}<0.001$. S.E. stands for the approximate standard error; C.R. stands for the critical ratio, which is the parameter estimate divided by an estimate of its standard error.

Table 5. Estimation of the Risk Score Covariance.

\begin{tabular}{|c|c|c|c|c|c|c|}
\hline \multicolumn{2}{|c|}{ Latent variables } & \multicolumn{2}{|r|}{ Estimate } & \multirow{2}{*}{$\frac{\text { S.E. }}{0.322}$} & \multirow{2}{*}{$\frac{\text { C.R. }}{3.313}$} & \multirow{2}{*}{$\frac{\mathrm{P}}{* * *}$} \\
\hline $\mathrm{S} 1$ & $<--->$ & S2 & 1.065 & & & \\
\hline $\mathrm{S} 1$ & $<--->$ & S3 & 0.765 & 0.267 & 2.862 & $0.004 * *$ \\
\hline $\mathrm{S} 1$ & $<--->$ & S4 & 0.083 & 0.126 & 0.655 & 0.513 \\
\hline $\mathrm{S} 1$ & $<--->$ & S5 & 0.045 & 0.125 & 0.359 & 0.720 \\
\hline $\mathrm{S} 2$ & $<--->$ & S3 & 0.912 & 0.283 & 3.226 & $0.001 * * *$ \\
\hline $\mathrm{S} 2$ & $<--->$ & S4 & 0.037 & 0.121 & 0.306 & 0.760 \\
\hline $\mathrm{S} 2$ & $<--->$ & S5 & 0.083 & 0.127 & 0.653 & 0.514 \\
\hline $\mathrm{S} 3$ & $<--->$ & S4 & 0.026 & 0.108 & 0.243 & 0.808 \\
\hline $\mathrm{S} 3$ & $<--->$ & S5 & 0.127 & 0.122 & 1.040 & 0.298 \\
\hline $\mathrm{S} 4$ & $<--->$ & S5 & -0.030 & 0.081 & -0.365 & 0.715 \\
\hline
\end{tabular}

approximate standard error; C.R. stands for the critical ratio, which is the parameter estimate divided by an estimate of its standard error.

In SEM applications, the overall fitness of the structural model is also needed to assess the goodness-offit tests in order to demonstrate the statistical reliability. The results of the schedule risks management model are discussed below. First, a recommended level of /df, where $\mathrm{df}$ is the degree of freedom, is usually greater than 5. The value $/ \mathrm{df}=1469.9 / 260=5.65$ in this case demonstrates a good match. P-value $=0.52>0.05$ suggests the statistical result is no significant and the proposed model is consistent with the observed data. Chi- square test is found to be extremely sensitive to the sample size. As a result, a variety of alternative goodnessof-fit indices have been developed to supplement the chisquare statistic. The Goodness-of-Fit Index $(\mathrm{GFI})=0.953$, the Comparative Index $(\mathrm{CFI})=0.976$, and the Root Mean Square Error of Approximation (RMSEA) $=0.014$ which are greater or less than suggested acceptable levels of $>0.95,>0.9,<0.05$, respectively, implying that the significance of variables to the model is augmented. Then, each cause of delay has a strong connection with its grouped class and significant influences on project schedule delay and other causes of delay.

In this case, the confirmatory factor analysis demonstrates a satisfied hypothesis testing result. However, possibilities still exist that the fitness tests might reject the original hypotheses in similar practices. In that case, the model fitting adjustment needs to be conducted. If still not satisfied, exploratory factor analysis could be conducted in order to identify potential underlying risk factors.

\subsection{Risk response process}

Understanding the direct or indirect relationships between risk factors would help practitioners take effective risk response actions. Based on the results of confirmatory factor analysis, several risk countermeasures have been adopted in order to address the schedule risks. From the project point of view, the corresponding risk countermeasures are conducted respectively for each risk item, and the general risk control is intended for arranging all the risk mitigation measures in an effective way. Updating for the risk management loop is conducted periodically, usually by month, and the final risk management result is thus well-controlled.

By taking the management and organization risks section from the SHAT2 risk register for an example,K1, $\mathrm{K} 2$ and $\mathrm{K} 3$ are addressed simultaneously due to their strong inner correlations. Corresponding risk countermeasures focus on doing good personnel arrangements. The airport headquarters need to pay more attention on the working staffs' personal goal achievements to make sure understanding their personal development plan and aligning to be consistent with the direction of the company and personal development arrangements. For K4 and K5 which have to be treated respectively, communications with the external interface and the general contracting office need to be maintained smoothly during the period of construction. Coordination between the main contractors keeps information flow spreading among the construction sites and, as a result, the human resources department could consider assign certain number of engineers working on site in order to identify and solve problems in time.

In general, schedule risks management results for both SHAT2 and TC are shown in Figure 5 that demonstrates the proposed risk management method could identify, evaluate and response the schedule risks effectively toward megaprojects. 

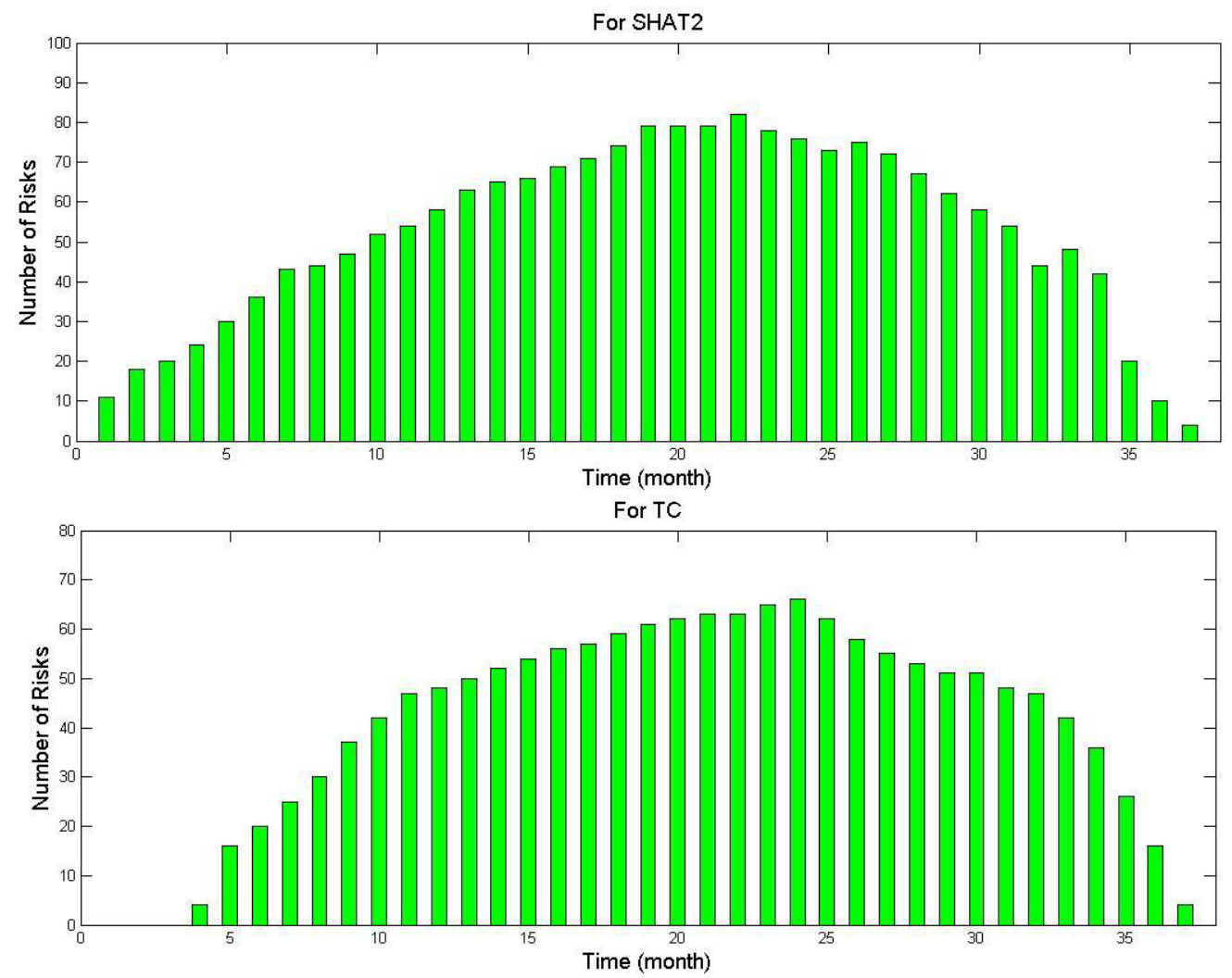

Figure 5. OutRisk control results for the Shanghai hongqiao airport terminal 2 and Traffic Center.

\section{Conclusion}

This study mainly focused on developing an efficient risk management method to address the schedule delays problems for transportation megaprojects. Taking the inner correlation and dependencies of megaproject schedule risks into consideration, this paper develops a statistical schedule risk management model for transportation megaprojects. Within the process, two techniques, the risk register and the structural equation modeling (SEM), are integrated for describing and quantifying the scores for each risk item. Survey results are collected from five aspects such as probability of risk events, consequence of risk events, and complexity of risk responsible owner's structure, reaction time, and time lasting for risk countermeasures. Then, two subprojects of the Shanghai Hongqiao Integrated Transport Hub (SHITH) are selected to demonstrate the applicability of the proposed model. Lessons learned from the proposed megaprojects demonstrate that the proposed risk management method could effectively identify, evaluate and response the schedule risks for megaprojects. Correlations among schedule risk characteristics are addressed, and the application simplicity of methodology is maintained.

Based on the SEM results, this study described and quantified the different aspects of schedule delay risks for transportation megaprojects. However, one limitation of this study is the relatively small sample size, as the structural equation modeling is a large sample technique. Nevertheless, this is the first study to our knowledge that examines the interrelationships existing within observable variables affecting project planning in order to understand how the individual variables work together in influencing planning effectiveness. Furthermore, despite the relatively small size of the sample, the hypothesized model provided a good explanation of how the project planning process interacts with its environment, and how these interactions influence project-planning effectiveness. Further work will focus on cross-validating the developed covariance structure model using data drawn from a larger sample, and data collected from other geographical locations.

\section{References}

1. B. Flyvbjerg, N. Bruzelius, \& W. Rothengatter, Megaprojects and risk: An anatomy of ambition, Cambridge University Press, Cambridge, (2003)

2. M. Pacione, Dubai, Cities, 22, no. 3, pp. 255-265, (2005)

3. K. Beck \& C. Andres, Extreme programming explained: Embrace change, Addison-Wesley Professional, Boston, (2004)

4. M. Giezen, Keeping it simple? A case study into the advantages and disadvantages of reducing complexity in mega project planning, International Journal of Project Management, 30, no. 7, pp. 781790, (2012)

5. W. R. Scott, R. E. Levitt, \& R. J. Orr, Global projects: Institutional and political challenges, Cambridge University Press, Cambridge, (2011)

6. PMI, A guide to the project management body of knowledge (5th ed.): Project Management Institute, Inc., Newtown Square, (2013) 
7. H. P. Berg, Risk management: Procedures, methods and experiences, Rsik Management, 1, no. 6, pp. 7995, (2010)

8. KPMG, How to successfully manage your megaproject, KPMG International Cooperative, http://www.kpmg.com

9. /us/en/issuesandinsights/articlespublications/pages/h ow-to-manage-mega-project.aspx. Accessed March 5, (2013)

10. D. Cooper, S. Grey, G. Raymond, \& P. Walker, Project risk management guidelines: Managing risk in large projects and complex procurements, John Wiley \& Sons, Hoboken, (2005)

11. O. Renn, The role of risk perception for risk management, Reliability Engineering \& System Safety, 59, no. 1, pp. 49-62, (1998)

12. H. Drummond, MIS and illusions of control: an analysis of the risks of risk management, Journal of Information Technology, 26, no. 4, pp. 259-267, (2011)

13. H. F. Cervone, Project risk management, OCLC Systems \& Services, 22, no. 4, pp. 256-262, (2006)

14. C. Traeger, Conducting a business impact analysis, Faulkner Information Services, Docid: 0018494, (2005)

15. Z. F. Lansdowne, Risk matrix: an approach for prioritizing risks and tracking risk mitigation progress, Proceedings of the 30th Annual Project Management Institute, Philadelphia, PA, October, pp. 10-16, (1999)

16. T. Kendrick, Identifying and managing project risk: essential tools for failure-proofing your project, AMACOM Div American Mgmt Assn., New York, (2003)

17. S. H. Han, D. Y. Kim, H. Kim, \& W. S. Jang, A web-based integrated system for international project risk management, Automation in Construction, 17, no. 3, pp. 342-356, (2008)

18. V. T. Luu, S. Y. Kim, N. V. Tuan, \& S. O. Ogunlana, Quantifying schedule risk in construction projects using Bayesian belief networks, International Journal of Project Management, 27, no. 1, pp. 39-50, 2009
19. P. Love, C. Sing, X. Wang, D. Edwards, \& H. Odeyinka, Probability distribution fitting of schedule overruns in construction projects, Journal of the Operational Research Society, 64, no. 8, pp. 12311247, (2013)

20. A. Öztaş, \& Ö. Ökmen, Judgmental risk analysis process development in construction projects, Building and Environment, 40, no. 9, pp. 1244-1254, (2005)

21. Ö. Ökmen \& A. Öztaş, Construction project network evaluation with correlated schedule risk analysis model, Journal of Construction Engineering and Management, 134, no. 1, pp. 49-63, (2008)

22. D. Schatteman, W. Herroelen, S. Van de Vonder, \& A. Boone, Methodology for integrated risk management and proactive scheduling of construction projects, Journal of Construction Engineering and Management, 134, no. 11, pp. 885893, (2008)

23. M. Vanhoucke, On the dynamic use of project performance and schedule risk information during projecttracking, Omega, 39, no. 4, pp. 416-426, (2011)

24. S. F. Moosavi \& O. Moselhi, Schedule assessment and evaluation, Construction Research Congress 2012: Construction Challenges in a Flat World, West Lafayette, pp. 535-544, (2012)

25. G. Jia, F. Yang, G. Wang, B. Hong, \& R. You, A study of mega project from a perspective of social conflict theory, International Journal of Project Management, 29, no. 7, pp. 817-827, (2011)

26. B. M. Byrne, Structural equation modeling with AMOS: Basic concepts, applications, and programming, Routledge, (2013)

27. M. Mainul Islam \& O. O. Faniran, Structural equation model of project planning effectiveness, Construction Management and Economics, 23, no. 2, pp. 215-223, (2005)

28. K. Molenaar, S. Washington, \& J. Diekmann, Structural equation model of construction contract dispute potential, Journal of Construction Engineering and Management, 126, no. 4, pp. 268277, (2000) 